\title{
Erratum to: Mechanical response and stability analysis of rock mass in high geostress underground powerhouse caverns subjected to excavation
}

\author{
LI Biao(李彪) ${ }^{1}$, DING Quan-fu(丁泉富) $)^{1}$, XU Nu-wen(徐奴文) ${ }^{2}$, LEI Yi-fan(雷艺繁) ${ }^{2}$, \\ XU Yuan(许媛) ${ }^{3}$, ZHU Zhong-ping(朱忠平) ${ }^{4}$, LIU Jing-fei(刘金飞) $)^{5}$
}

1. School of Geoscience and Technology, Southwest Petroleum University, Chengdu 610500, China;

2. State Key Laboratory of Hydraulics and Mountain River Engineering, College of Water Resource and Hydropower, Sichuan University, Chengdu 610065, China;

3. Department of Engineering Science, University of Oxford, OX5 1PF, United Kingdom;

4. Sichuan Dadu River Shuangjiangkou Hydropower Development Co., Ltd., Maerkang 624099, China;

5. Power China Chengdu Engineering Co., Ltd., Chengdu 610072, China

(C) Central South University Press and Springer-Verlag GmbH Germany, part of Springer Nature 2021

Erratum to: J. Cent. South Univ. (2020) 27: 2971-2984

DOI: https://doi.org/10.1007/s11771-020-4506-8

Because of an unfortunate mistake during the production of this article, the initial printed versions and the online PDF had incorrect DOI numbers. The DOI has now been corrected and synchronized with the correct DOIs of the HTML versions.

Corresponding author: XU Nu-wen, PhD, Professor; Tel: +86-28-85406701; E-mail: xunuwen@scu.edu.cn; ORCID: https://orcid.org/ 0000-0001-7714-7930 